\title{
Feasibility of n-type crystalline silicon wafer for fabricating Industrial Silicon Solar Cell with significant acceptable efficiency in near future
}

\author{
U. Gangopadhyay, S.Das, S.Jana, P.Ghosh \\ Meghnad Saha Institute of Technology, TIG, Kolkata-700150, India
}

\begin{abstract}
We are presenting the feasibility study on the industrial solar cell processing with $n$-type crystalline silicon. For the performing feasibility study, we have introduced SWOT (strength-Weakness-Opportunities, \& Threat) analysis of crystalline solar cell with n-type crystalline silicon. Cost comparison of crystalline silicon $p$ type wafer and n-type wafer has also been given in this paper for better understanding the cost benefit of the total integrated crystalline silicon production line. An additional motivation for highlighting of already existing industrial process sequence for $n$-type silicon is incorporating in this paper.
\end{abstract}

Keywords: Feasibility; n-type crystalline silicon; Solar cell; SWOT analysis

\section{Introduction}

The use of n-type material has several advantages over the use of p-type. N-type silicon has been proven to have a higher tolerance to common transition metal impurities, like Fe [1,2,3 ] such as those present in silicon produced from quartz and carbon (via metallurgical routes), potentially resulting in higher minority carrier life time diffusion lengths compared to p-type substrates [4,5]. Because of this property, n-type material could have a higher tolerance for lower-quality feedstock [6, 7]. Secondly, in n-type material boron-oxygen complexes are absent, and therefore it will not suffer from Light Induced Degradation (LID) $[8,9,10]$. In lowcost silicon feedstock materials, like compensated upgraded metallurgical grade (UMG) silicon, investigations have been applied to determine the influence of boron complex formations over solar cells performances. In addition, n-type silicon was reported to be a material with higher carrier lifetime [11] due to the reduced sensibility towards the most of the metallic impurities compared to p-type silicon due to a reduced capture crosssection for minority carriers [12]. Exceptionally high minority carrier lifetimes have been measured in $n$-type multi-crystalline silicon ( $\mathrm{mc}-\mathrm{Si}$ ) grown by directional solidification and subjected to phosphorus gettering. The highest effective lifetimes, up to $1.6 \mathrm{~ms}$ averaged over several grains and $2.8 \mathrm{~ms}$ within some of them, were measured for relatively lowly doped, $2-3 \Omega \mathrm{cm}$, wafers. The lifetime was found to decrease for lower resistivities, still reaching $500 \mu \mathrm{s}$ for $0.9 \Omega \mathrm{cm}$ and $100 \mu \mathrm{s}$ for $0.36 \Omega \mathrm{cm}$ [13]. The intra-grain minority carrier lifetime measured in the $0.65 \mathrm{ohm} . \mathrm{cm}$ mc-Si devices was $35-135 \mathrm{~ms}$ after a $900{ }^{\circ} \mathrm{C}, 30 \mathrm{~min}$ phosphorus diffusion gettering, up from about $10 \mathrm{~ms}$ before gettering.[14]. Other researchers have also measured high lifetimes in mc- Si. An aluminium alloying step has also been found to be effective in increasing the minority carrier lifetime, which reached values up to $190 \mathrm{~ms}$ in 0.8 Ohm.cm materials [15]

Not specific for $\mathrm{n}$-type, but in practice easier to realize on this material, compared to the traditional ptype cells with full Al back surface field, or PERC configuration cells with blanket metallization on the rear, is the possibility to create bi-facial cells and modules [16].

Moreover, the fraction of crystalline silicon cells made from p-type material is close to $95 \%$, and only somewhat more than $5 \%$ is made from n-type material. This is caused mostly by an insufficient development and industry implementation of the n-type cell processes for multi-crystalline substrates. But recently, n-type silicon materials have received much interest as they are considered promising candidates for future generations of high-efficiency solar cells. Although the total amount of n-type crystalline silicon solar cells is limited, two important manufacturers, SunPower [17] and Sanyo [18], are using this material to produce high-efficiency solar cells. On these cell types efficiencies of $24 \%$ and $23 \%$, respectively, have been reached.

In conclusion, high minority carrier lifetimes and competitive diffusion length have been reported in multi-crystalline n-type material. In addition, n-type mc-Si demonstrated resilience to common contaminations during process or wafer formation thanks to a lower capture cross section for holes than for electrons, for many impurities. Reduction of recombination activity after gettering in $\mathrm{n}$-type mc-Si has been shown to be as good as in p-type material. Crystallographic defects commonly introduced during wafer growth, such as grain boundaries or dislocations, may exhibit low recombination strength in n-type mc-Si, but literature reports about this vary. All these features combined with an appropriate fabrication process would lead to high efficiency silicon solar cells based on n-type mc-Si substrates. 
Feasibility of n-type crystalline silicon wafer for fabricating Industrial efficiency in near future

In this paper we report the feasibility study on the industrial solar cell processing with n-type crystalline silicon. For the performing feasibility study, we have introduced SWOT (strength-WeaknessOpportunities, \& Threat) analysis of crystalline solar cell with n-type crystalline silicon.

\section{SWOT Analysis}

SWOT analysis provides a framework for visioning by helping the planners to identify and prioritize the organization's goals in terms of technology and to further identify the strategies of achieving them. Visioning is best aided by SWOT analysis.

"SWOT" is a simple acronym for Strengths, Weaknesses, Opportunities and Threats. SWOT analysis consists of the following two activities:

- An assessment of the organization's internal Strengths and Weaknesses

- An assessment of the Opportunities and Threats posed by its external environment

Internal Reality:

N-type crystalline wafer \& Solar Cell using n-type crystalline wafer Analysis

\begin{tabular}{|c|c|}
\hline & \\
\hline $\begin{array}{c}\text { Strengths } \\
\text { (Utilize) }\end{array}$ & $\begin{array}{c}\text { Opportunities } \\
\text { (Exploit) }\end{array}$ \\
\hline Weaknesses \\
(Avoid or Fix)
\end{tabular}

External Reality:

Environmental Analysis 
second is detrimental to mc-Si. To avoid this problem; our boron emitter diffusion normally followed at moderate temperature of about $930^{\circ} \mathrm{C}$. Effective lifetime measurements of the bulk before and after theBBr3 open-tube furnace diffusion confirmed constant values averaged over the entire wafer and thus suggest no thermal degradation of the mc-Si.

d. In spite of several advantages, at present, more than $85 \%$ of the silicon solar cells produced by the industry are based on p-type substrates. This is caused mostly by an insufficient development and industry implementation of the n-type cell processes for multi-crystalline substrates

\section{Opportunities:}

a. N-type silicon has been proven to have a higher tolerance to common transition metal impurities, such as those present in silicon produced from quartz and carbon. This tolerance could potentially result in higher minority carrier diffusion lengths compared to p-type substrates. Boron-oxide defects that lead to light- induced degradation is also absent which is ultimately increase minority carrier diffusion length. In spite of these advantages, at present, more than $85 \%$ of the silicon solar cells produced by the industry are based on p-type substrates. This is caused mostly by an insufficient development and industry implementation of n-type cell processes.

b. One of the major development areas of the n-type Si solar cell process remains the process of passivation of the front side boron emitter. Since the conventional way to passivate $n+$ emitters for the p-type solar cell process, using a PECVD-SiNx layer, results in a poor or no passivation for $\mathrm{p}+$ emitters, a new way of passivating p+ surfaces needs to be developed. Mihailetchi et al have developed a new method to passivate $\mathrm{p}+$ emitters which brought new potential to the $\mathrm{n}$-type $\mathrm{Si}$ industrial solar cell process. This method relies on the same PECVD SiNx technology as is widely used in industry to passivate $\mathrm{n}+$ (Phosphorus) emitters.

c. The new method is industrially applicable with no substantial increase in cost or process times.

d. N-type silicon material has presented high potential for high-efficiency solar cells fabrication process sequence. Superior carrier lifetime performance has been showed in $\mathrm{n}$-type multi-crystalline EG ingot. These measured carrier lifetimes are close to typical p-type mono-crystalline silicon. This type of material could offer a better cost benefit than p-type mono- and multi-crystalline silicon. To attempt costs reduction in material production and simultaneous improvement of the performance of solar cells compensated UMG silicon is a great candidate. In this material, carrier lifetime measurements have showed high performance in n-type zones. Lifetime values are at least five times higher than in p-type neighbour zone. The implementation of a standard industrial process to n-type silicon technology in the near future will allow a complete exploitation of $\mathrm{n}$-type silicon potentialities.

e. UMG polysilicon $(\sim 6 \mathrm{~N})$ can be used for growing $\mathrm{n}$-type multicrystalline Ingot followed by wafering. A significant cost benefit approach because probable polysilicon feed stock for growing of p-type multi crystalline ingot is at least $8 \mathrm{~N}$ whose tentative market price is around US $\$ 50-55 / \mathrm{Kg}$. Whereas the market price of UMG polysilicon is around US $\$ 30-35 / \mathrm{Kg}$.

f. Some reputed Research R \& D Lab. and Solar cell Industries already reported the possibilities for using n-type crystalline silicon as different high efficiency fabrication approach.

\section{Threats:}

a. Brendel etal. reported that $n$-type mc-Si material has no significant advantage over $p$-type mc-Si, assuming that the most detrimental contaminants in today's mc-Si materials are $\mathrm{Fe}$ and $\mathrm{Cr}$. Hence, we conclude that $n$-type mc-Si is, in general, not suitable as a high-efficiency solar cell material. On the contrary, $n$-type $\mathrm{Cz}$-Si has been shown to be a nearly perfect high-efficiency material, as it typically possesses stable lifetimes in the millisecond range.

\section{Why N-type}

In the scenario, crystalline silicon, in particular $n$-type silicon is a great candidate because the potential of this reliable material is certainly not exhausted yet and the next generation of technology is just starting to enter the market. At present, almost $90 \%$ of worldwide solar cells fabrication is based on crystalline silicon technology and most of these cells are produced from p-type silicon.

The well-establish p-type solar cell technology is most subject to light-induced degradation (LID) than n-type technology. It could be attributed to the formation of a boron-oxygen complex leading to lower minority carrier diffusion length. This phenomenon appears to be less critical in n-type silicon. In low-cost silicon feedstock materials, like compensated upgraded metallurgical grade (UMG) silicon, investigations have been applied to determine the influence of boron complex formations over solar cells performances. In addition, $\mathrm{n}$ type silicon was reported to be a material with higher carrier lifetime due to the reduced sensibility towards the 
most of the metallic impurities compared to p-type silicon due to a reduced capture cross-section for minority carriers.

The minority carrier lifetime and minority carrier diffusion length are the most important parameter to characterize the quality of silicon used in photovoltaic applications. A precise determination of the behavior of physical properties of the silicon ingots requires measurement techniques that offer a clear comprehension of carrier interactions in the material. The defect characterization in silicon wafers permits the identification of recombination centers (impurities, dislocations, grains boundaries etc.). This procedure allows us to establish a plan of action to reduce or eliminate recombinant-active defects, providing a reasonable start-point for solar cells process and performance optimization.

N-type silicon material has presented high potential for high-efficiency solar cells applications. Superior carrier lifetime performance has been showed in n-type multi-crystalline EG ingot. These measured carrier lifetimes are close to typical p-type mono-crystalline silicon. This type of material could offer a better cost benefit than p-type mono- and multi-crystalline silicon.

To attempt costs reduction in material production and simultaneous improvement of the performance of solar cells, compensated UMG silicon is a great candidate. In this material, carrier lifetime measurements have showed high performance in n-type zones. Lifetime values are at least five times higher than in p-type neighbor zone. The implementation of a standard industrial process to $\mathrm{n}$-type silicon technology in the near future will allow a complete exploitation of n-type silicon potentialities.

It has been established that during the P-diffusion step in n-type silicon an impurity redistribution takes place and that both an internal and an external gettering process occurs, with GBs(Grain Boundaries) acting as secondary gettering sinks for impurities. It has been found that this impurity redistribution process is thermally activated; this result may be useful for a future optimization of the solar cell process, taking particular attention to the time and annealing temperature.

Despite the intriguing effects of impurity segregation and precipitation at GBs, and the associated increase of their electrical activity, It has been confirmed that n-type feedstock's are compatible with high quality mc-Si, possibly better than that of the p-type materials, confirming that n-type-Si is a valid resource for photovoltaic applications.

The researchers have also developed a simple, new method, which they have patented, for substantially reducing electrical losses at the front of n-type solar cells, by 'passivating' the surface on which the light falls. This prevents charge carriers at the surface diffusing (recombining) and therefore no longer contributing to the electrical current from the cell. The new technology retains more charge carriers, thus increasing cell efficiency.

Efficiency varies from one type of wafer to another. The efficiency gain with n-type cells made from mono-crystalline wafers, compared with that of current p-type cells, is substantial - about 1 percent in absolute terms - while the fabrication process is similar to the normal p-type process in terms of cost and complexity. This may not seem like a major gain, but with the current standard 15-17\% conversion efficiency of solar cells a gain of $1 \%$ in absolute terms yields a relative gain of $6 \%$. In the case of n-type cells made from multicrystalline wafers the gain depends on the wafer quality, but it would seem to be comparable with that of mono-crystalline wafers.

As the fabrication process uses the same kind of manufacturing equipment as currently used to make ptype silicon cells, the process can be implemented in industry quickly, possibly just by making minor modifications to existing production lines. ECN intends to further develop and commercialize various types of solar cells based on this technology in the short and medium term.

Solar power could develop into the main source of sustainable energy. Solar cells convert sunlight directly into electricity. This type of energy conversion is regarded as one of the main applications in the worldwide sustainable energy system of the future. The new type of solar cell, combined with developments in the Crystal-clear Project, where cells are glued instead of soldered, and the technology for making extremely thin solar cells which can be made into solar panels up to eight times faster than at present, using the recently developed pilot line, are contributing to ECN's ambition to reduce the cost of solar power by improving the conversion efficiency of cells and allowing cheaper materials to be used. In the Netherlands, electricity from solar cells costs about twice as much as the consumer price of electricity from the grid, currently costing 50 cents per kilowatt hour. This should go down to 25 cents by 2015 and 10 cents or less by about 2030 .

Weeber etal. of ECN Solar Energy, Netherland already developed n-type solar cells on large area $(156.25 \mathrm{~cm} 2)$ multicrystalline and mono-crystalline $\mathrm{Cz}$ substrates, involving diffusion of phosphorus $\mathrm{BSF}$ and boron emitter, screen-printed metallization and firing through, leading to efficiencies of $16.4 \%$ on multicrystalline Si and $18.3 \%$ on Cz. Experiments on wafers of different base resistivity show that the optimum target resistivity for n-type multicrystalline silicon wafers lies between 1.5 to $4 \Omega \mathrm{cm}$ in order to maximize the efficiency output thorough the ingot.

September 22, 2009 - Researchers at the Fraunhofer Institute for Solar Energy Systems (ISE) have developed prototype $\mathrm{n}$-type silicon solar cells with conversion efficiency exceeding a record $23.4 \%$. 
P-type silicon solar cells are the most common ones today, but n-type cells offer better PV electricity production thanks to properties like greater impurity tolerance, and it does not suffer from light-induced degradation as does p-type $\mathrm{Cz}$ silicon. The end result is better efficiency or lowered manufacturing costs using less-expensive silicon, notes Martin Hermle, Fraunhofer ISE's group manager.

A $2 \times 2 \mathrm{~cm}^{2} \mathrm{n}$-type cell was shown to achieve $23.4 \%$ conversion efficiency; a bigger cell $\left(12.5 \times 12.5 \mathrm{~cm}^{2}\right.$, "using much simpler process stages close to industry practice" -- including a screen-printing application of the aluminum alloy emitter -- reached $18.2 \%$ efficiency. The researchers say they will further tweak the process technology to push the commercially-viable silicon solar cells to exceed $20 \%$ efficiency rates.

The directionally solidified (DS) multi-crystalline silicon (mc-Si) has become a dominant material in the fast growing PV market for solar cells because of its cost-effectiveness and excellent electronic properties. Nowadays commercial p-type mc-Si based solar cells achieve solar conversion efficiencies in the range of 15$16.4 \%$ with industrial standard processes, up to $17 \%$ with standard screen printing processes 1 and above $20 \%$ with more sophisticated solar cell designs.

Recently, n-type mc-Si has attracted attention as a short term solution to the main current problem for the photovoltaic industry: the silicon supply. A partial solution not yet on the market, is in fact the use of the ndoped silicon waste available from the semiconductor industry. For this purpose, in the last 3 years some works have been carried out on studies of the properties of n-type mc-Si and c-Si, and on the development and optimization of a solar cell process for n-type mc-Si. First results on solar cells based on n-type monocrystalline material using industrial processes have already shown excellent efficiencies exceeding $17 \%$, but some unknowns, concerning the specific role of certain impurities in a B-free material and that of their interaction with extended defects, still remain.

Sanyo has decided to increase the production capacity of HIT (Heterojunction with Intrinsic Thinlayer) solar cells annually from $165 \mathrm{MW}$ in 2006 to $600 \mathrm{MW}$ in 2010.The HIT solar cell is a unique highefficiency silicon solar cell, which results from our amorphous silicon (a- $\mathrm{Si}$ ) and crystalline silicon (c-Si) solar cell technologies. In order to further expand the use of solar modules, it is necessary to thoroughly reduce the power generating cost. With this goal, technologies for higher conversion efficiency and a thinner c-Si wafer are both important. As for the higher conversion efficiency, Sanyo has announced a plan to raise cell conversion efficiency to $23 \%$ in the laboratory.

The PERT cell structure also used for this n-type cell research is a reverse polarity structure compared to previously publish PERT cells on p-type substrates .A boron doped emitter is used. It has been commonly believed that the boron diffusion may cause excessive surface recombination compared to the phosphorus emitter.

SunPower Corporation is commercializing novel high-efficiency (20-22\%) silicon solar cells that can lower the cost and accelerate the growth of photovoltaics. These advantages include reduced silicon cost on a per-watt basis and reduce per-watt module construction and installation cost. With higher ell efficiency, there is more power generated per silicon wafer. SunPower is using low cost photovoltaic float-zone n-type silicon starting material (PV-FZ), recently available from Topsil.

SunPower has built a $25 \mathrm{MW} / \mathrm{year}$ production line in the Philippines and is now the process of ramping this factory to production level. This facility has space to expand to $100 \mathrm{MW} / \mathrm{Yr}$ production.

\section{Conclusion}

From The SWOT analysis, It has been observed that N-type silicon material has presented high potential for high-efficiency solar cells applications. Superior carrier lifetime performance has been showed in n-type multi-crystalline EG ingot. These measured carrier lifetimes are close to typical p-type mono-crystalline silicon. This type of material could offer a better cost benefit than p-type mono- and multi-crystalline silicon. To attempt costs reduction in material production and simultaneous improvement of the performance of solar cells compensated UMG silicon is a great candidate. In this material, carrier lifetime measurements have showed high performance in n-type zones. Lifetime values are at least five times higher than in p-type neighbour zone. The implementation of a standard industrial process to n-type silicon technology in the near future will allow a complete exploitation of n-type silicon potentialities.

\section{Acknowledgements}

The author would like to thank Prof. H.Saha, Prof. A.K.Barua, Dr. R. Bhattacharya and Prof. S. Dutta of CEGESS, Bengal Engineering \& Science University, Sibpur for cooperation and stimulating discussions about the topic. Meghnad Saha Institute of Technology, TIG provides me the infrastructural support for carrying out research activity in this area. The authors also gratefully acknowledge the DST, Govt. of India for financial support for carrying out solar cell related research activity. 


\section{References}

[1] D. Macdonald and L.J. Geerligs, Appl. Phys. Lett. (2008) 92 p4061.

[2] J.E. Cotter et al., 15th Workshop on Crystalline Silicon Solar Cells \& Modules: Materials and Processing 2005 , p3.

[3] N. Guillevin et al. 19th Workshop on Crystalline Silicon Solar Cells \& Modules: Materials and Processes 2009 , p26.

[4] D. MacDonald, L.J. Geerligs, Applied Physics Letters, 85, (2004) 4061.

[5] J.E. Cotter et al., 15th Workshop on Crystalline Silicon Solar Cells \& Modules: Materials and Processes (2005) 3.

[6] A. Cuevas et al., Appl. Phys. Lett. 81 (2002) p4952.

[7] S. Martinuzzi et al., Prog. Photovolt.: Res. Appl. 17 (2009) p297.

[8] J. Schmidt et al. 26th IEEE PVSC Anaheim, 1997,p13.

[9] S. Glunz et al., 2nd WCPEC Vienna 1998 p1343.

[10] J. Schmidt et al., Formation and Annihilation of the Metastable Defect in Boron-Doped Czochralski Silicon,29th IEEE PVSC, New Orleans, 2002

[11] A. Cuevas, M.J. Kerr, C. Samundsett, F. Ferrazza, G. Coletti, Millisecond minority carrier lifetimes in n-type multicrystalline silicon, Appl. Phys. Lett. 81 (2002) 4952-4954.

[12] A.F.B. Braga, et al., Sol. Energy Mater. Sol. Cells (2007), doi:10.1016/j. solmat.2007.10.003.,[6] S. Martinuzzi, et al., Proceedings of the 31st IEEE PVSEC, Orlando, 2005

[13] "Millisecond minority carrier lifetimes in n-type multicrystalline silicon" Andres Cuevas, Mark J. Kerr, Christian Samundsett, Francesca Ferrazza, and Gianluca Coletti, Appl. Phys. Lett. 81, 4952 (2002).

[14] A. Rohatgi and S. Narashima, "High-efficiency cell fabrication on low defect density materials," in Proceedings of the Sixth Workshop on the Role of Impurities and Defects in Silicon Device Processing, edited by B. Sopori National Renewable Energies Laboratory, Golden, CO, 1996!, pp. 127-138.

[15] P. Lo"lgen, A. Rohatgi, P. Sana, W. C. Sinke, A. W. Weeber, C. Leguijt, R. A. Steeman, and J. A. Eikelboom, in Proceedings of the Twelfth European Photovoltaic Solar Energy Conference, Amsterdam, $1994 \sim$ H. S. Stephens and Associates, Felmersham, United Kingdom!, p. 1778.

[16] P. Sánchez-Friera et al., Development and characterisation of industrial bi-facial PV modules with ultrathin screen-printed solar cells, 22nd EPVSEC Milan 2007

[17] us.sunpowercorp.com

[18] www.sanyo.com/solar 